\title{
The effects of small-scale convection in the shallow lithosphere of the North Atlantic
}

\author{
Jeremías Likerman ${ }^{\mathrm{a}, \mathrm{b}}$, Sergio Zlotnik ${ }^{\mathrm{c}}$, Chun-Feng Li ${ }^{\mathrm{d}, \mathrm{e}}$ \\ ${ }^{a}$ Instituto de Estudios Andinos Don Pablo Groeber (IDEAN), CONICET - Universidad de Buenos \\ Aires, Buenos Aires, Argentina \\ ${ }^{b}$ Universidad de Buenos Aires, Facultad de Ciencias Exactas y Naturales, Departamento de Ciencias \\ Geológicas, Buenos Aires, Argentina \\ ${ }^{c}$ Laboratori de Càlcul Numèric (LaCàN), Departament d'Enginyeria Civil i Ambiental, Universitat \\ Politècnica de Catalunya, Barcelona, Spain \\ ${ }^{d}$ Institute of Marine Geology and Resources, Zhejiang University, Zhoushan, China \\ ${ }^{e}$ Laboratory for Marine Mineral Resources, Qingdao National Laboratory for Marine Science and \\ Technology, Qingdao, China
}

\begin{abstract}
Curie point depth can be used as a proxy for plate temperatures. Data from the North Atlantic $\left(\mathbf{1 0}^{\circ}-\mathbf{5 0}{ }^{\circ} \mathbf{N}\right)$ is used here to determine if the observed oscillations and patterns in Curie depths could be a sub product of small-scale thermal instabilities arising at the bottom of the lithospheric plates. Our numerical models suggest that small-scale convection (SSC) cells could produce thermal perturbations at isotherms as low as the Curie point. These results are compatible with North Atlantic observations in terms of wavelengths (150 to $300 \mathrm{~km})$, amplitudes $(\sim 4 \mathrm{~km})$ and orientations of the instabilities. Observed Curie-point depth oscillations before the onset (70 to $90 \mathrm{Myr}$ ) of SSC could also be linked to other different processes. We suggest that, in the case of the North Atlantic lithosphere, the spreading rate variation and the melt and upwelling could be intricately linked and cause a different pattern of SSC.

Keywords: Composition of the mantle, Numerical modelling, Dynamics: gravity and tectonics, Atlantic Ocean, Dynamics of lithosphere and mantle
\end{abstract}

\section{1. Introduction}

The Curie-point depth is known as the depth at which magnetic minerals pass from a

3 ferromagnetic to paramagnetic state under the effect of increasing temperature (Nagata,

Email address: jlikerman@gl.fcen.uba.ar (Jeremías Likerman)

Preprint submitted to Geophysical Journal International

July 12, 2021 
4 1961). Curie points form a theoretical isotherm of Curie temperatures (e.g., $\sim 580{ }^{\circ} \mathrm{C}$ 5 for magnetite) at the base of the magnetic layer. Geomagnetic anomalies can be used to 6 study magnetic structures above the Curie point depth. Based on the Earth Magnetic 7 Anomaly Grid (EMAG2; Maus et al., 2009), Li et al. (2013) constrained North Atlantic 8 Curie depths by means of magnetic anomaly inversion with a fractal magnetization model, 9 and showed that Curie depths exhibit a large oscillating and heterogeneous patterns with a wavelength between 200 and $400 \mathrm{~km}$, approximately (Figure 1). They interpret that 11 the oscillations might be a consequence of sublithospheric small scale convection (SSC, 12 Parsons \& McKenzie, 1978; Eberle \& Forsyth, 1995; Huang \& Zhong, 2005).

$\mathrm{SSC}$ is one of the proposed mechanisms invoked to explain the divergence between 14 the theoretical cooling predictions and the observables on oceanic plates older than $\sim 70$ 15 Myr (e.g. Zlotnik et al., 2008). For example, the difference between the observed Pacific 16 seafloor topography over 100 Myr can be $1 \mathrm{~km}$ shallower than the predictions, and at 150 17 Myr the difference could reach $2 \mathrm{~km}$ (Stein \& Stein, 1992). SSC derives from thermal 18 boundary layer (TBL) instabilities below the oceanic lithosphere. In this scenario, the 19 dripping of cold lithospheric material into the convective mantle is replaced with hot 20 mantle rocks, thus limiting the base of the ocean lithosphere from cooling (Richter, 1973; ${ }_{21}$ Parsons \& McKenzie, 1978; Davaille \& Jaupart, 1994). There have been considerable 22 efforts to understand the physics that rules the thermal instabilities of the SSC (Richter, 23 1973; Richter \& Parsons, 1975; Huang et al., 2003; Afonso et al., 2008; Zlotnik et al., 24 2008). It is known that the interaction between the large-scale convection and SSC tends 25 to form longitudinal rolls (also called 'Richter rolls') and transverse rolls, of which the 26 axis is parallel and perpendicular to the plate motion, respectively. Moreover, van Hunen 27 et al. (2003) concluded that longitudinal rolls may be dominant over transverse rolls if 28 the shearing due to plate motion is significant. The presence of either or both types of 29 rolls is still a matter of debate.

Because Curie points are well within the lithosphere (at depths between 5 and 45 $31 \mathrm{~km}$ ), it is not clear if SSC could propagate up its thermal anomalies from the Litho32 sphere-Asthenosphere Boundary (LAB) into the conductive lithosphere until those depths.

33 Moreover, the pattern of the Curie depth oscillations differs slightly between the North 34 Atlantic and the Pacific (Li et al., 2013, 2017; Li \& Wang, 2018). In the North Atlantic, 
oscillations show an alignment that favors ridge parallel directions, whereas in the Pacific

36 there is not a preferred direction.

37 In this work we examine the hypothesis that Curie depth anomalies could be a conse-

38 quence of small-scale convection processes. In addition we provide a possible explanation

39 of the different Curie depth patterns observed in the North Atlantic.

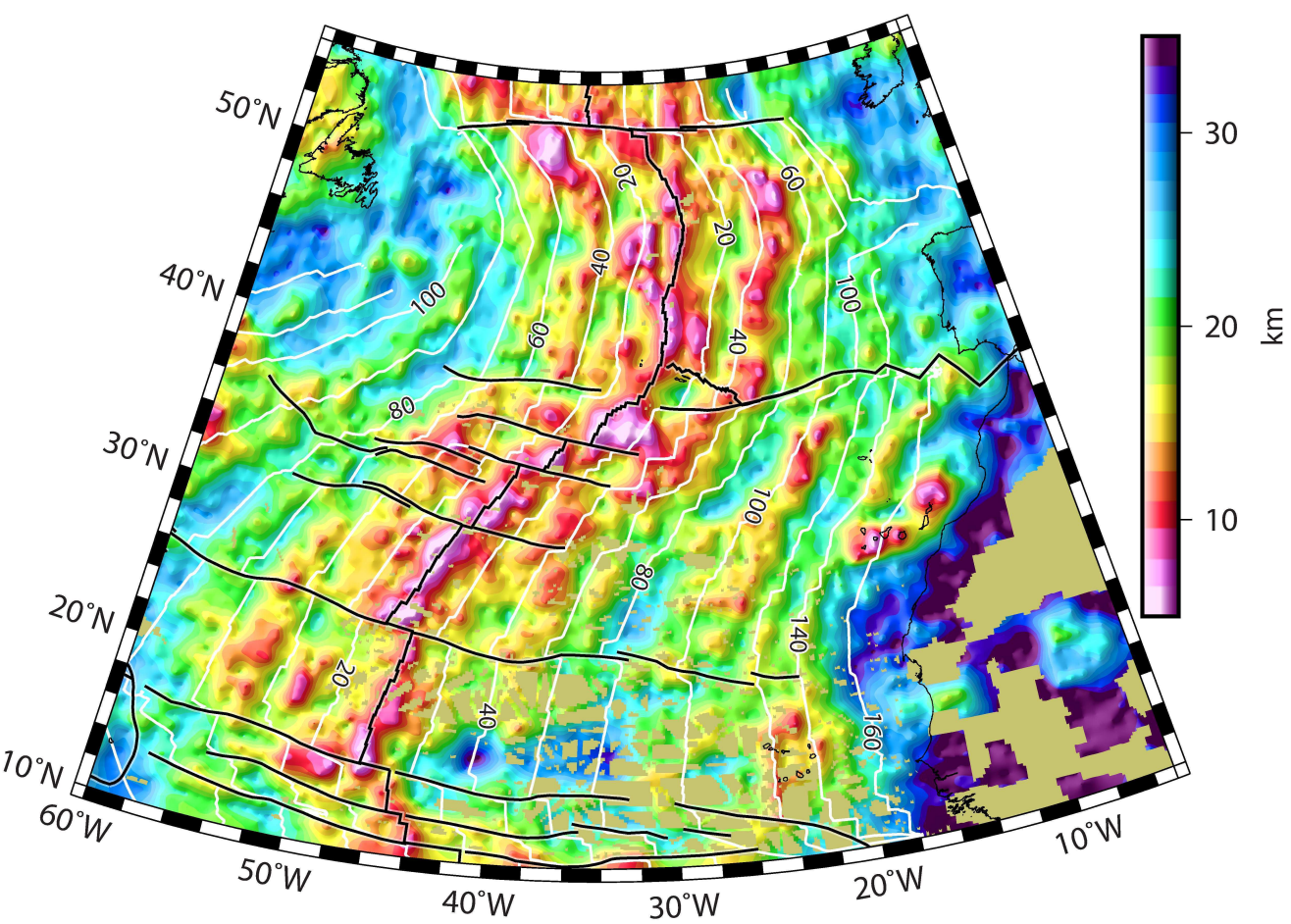

Figure 1: Curie depth map of the North Atlantic based on inversion of magnetic anomalies from EMAG2 (modified from Li et al., 2013), in Albers equal-area conic projection and calculated with a window size of $208.8 \times 208.8 \mathrm{~km}^{2}$. Thick black lines are fracture zones. Crustal isochrons (white lines) are based on Müller et al. (2008).

\section{Model setup}

In order to study SSC, we applied the particle-in-cell finite element code Underworld ${ }_{42}$ (Moresi et al., 2007). We performed 3D simulations based on the equations of conser43 vation of momentum, mass and energy under the assumptions of incompressibility and 
44 using the Boussinesq approximation. Velocity $u$, pressure $P$ and temperature $T$ are de-

45 termined by solving the conservation of momentum (Stokes equation), mass, and energy

46 equations:

$$
\begin{gathered}
\nabla \cdot\left(\eta \nabla^{s} u\right)+\nabla P=\rho g \\
\nabla \cdot u=0 \\
\rho C_{p}\left(\frac{\delta T}{\delta t}+u \nabla T\right)=\nabla \cdot(k \nabla T)+\rho f
\end{gathered}
$$

47 where the $\nabla^{s}$ is the symmetrized gradient, $\eta$ the viscosity, $\rho$ the density, $g$ the gravita-

48 tional acceleration vector, $C_{p}$ the isobaric heat capacity, $k$ the thermal conductivity, and

$49 f$ a heat source (sum of the decay of radioactive elements, adiabatic heating and shear

50 heating).

51 A general nonlinear rheology is implemented:

$$
\varepsilon=A\left(\sigma^{\prime} / \mu\right)^{n}(b / d)^{m} \exp \left(-\frac{E+P V}{R T}\right)
$$

52 where $d$ is the average grain-size, $\sigma$ the deviatoric stress second invariant, $A$ the pre-

53 exponential factor, $\mu$ the shear modulus, $b$ the length of the Burgers vector, $n$ the stress

54 exponent, $m$ the grain-size exponent, $E$ the activation energy, $V$ the activation volume,

55 and $R$ the gas constant. Table 1 describes the dimensional values used in this study.

56 Deformation in the mantle is governed by two main creep mechanisms: dislocation 57 creep and diffusion creep (Ranalli, 1995; Kirby, 1983). The first one is present in the 58 lithospheric mantle samples and the latter may be dominant at depths greater than 250-

$59300 \mathrm{~km}$. Due to this change in deformation mechanism with depth and given that both

${ }_{60}$ act simultaneously in the mantle, an effective viscosity $\eta_{\text {eff }}$ is computed as the harmonic

${ }_{61}$ mean of two different viscosities $\left(\eta_{\text {disl }}\right.$ and $\left.\eta_{\text {diff }}\right)$ from both creep mechanisms:

$$
\frac{1}{\eta_{\mathrm{eff}}}=\left(\frac{1}{\eta_{\mathrm{diff}}}+\frac{1}{\eta_{\mathrm{disl}}}\right)
$$

Calculations are performed in a rectangular box of 4000-6000 km long (depending on 63 the model), $1000 \mathrm{~km}$ wide and $660 \mathrm{~km}$ deep using $384 \times 96 \times 96$ elements. We impose a 


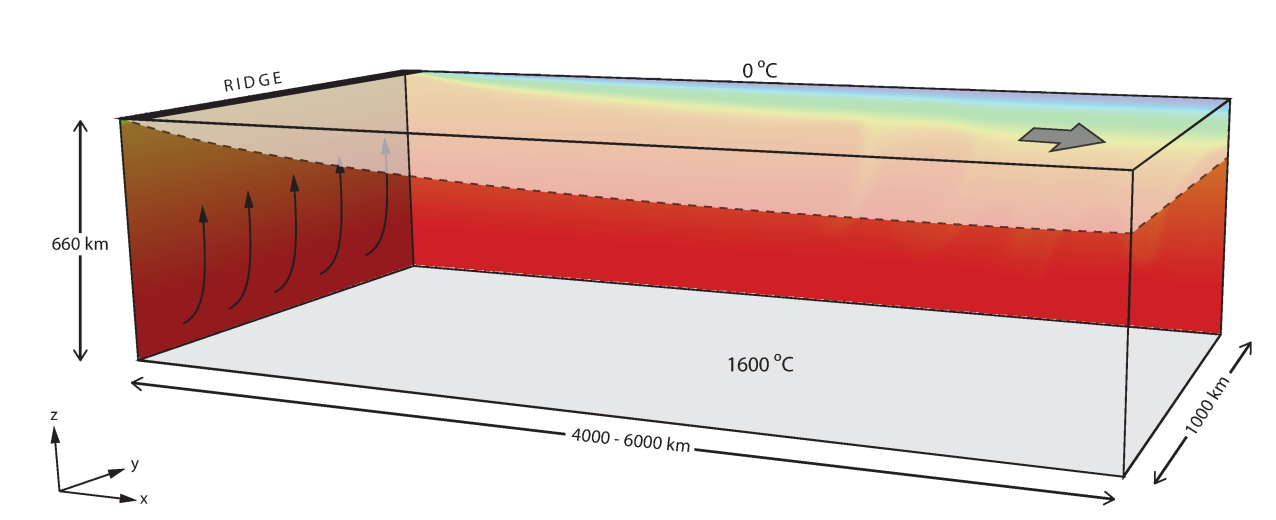

Figure 2: Schematic model setup. A constant temperature of $1660^{\circ} \mathrm{C}$ is defined at the bottom of the
model. Left boundary has a constant inflow of young lithosphere, whereas the old lithosphere outflows

Figure 2: Schematic model setup. A constant temperature of $1660^{\circ} \mathrm{C}$ is defined at the bottom of the
model. Left boundary has a constant inflow of young lithosphere, whereas the old lithosphere outflows through the right wall. Bottom and top boundaries are closed and free-slip.

velocity boundary condition at the top surface of the box, in the direction of increasing $\mathrm{x}$ coordinate, to control the ocean ridge spreading rate. Inflow material is allowed at the left wall where the ridge is located, whereas outflow is permitted at the right wall, and free-slip conditions are set at bottom, back and front walls (Figure 2). Temperature is fixed at the model surface and bottom at $0^{\circ} \mathrm{C}$ and $1600^{\circ} \mathrm{C}$, respectively. At starting time $t_{0}$, lithosphere thickness is $80 \mathrm{~km}$ with a conductive temperature structure above the base of the lithosphere, where the temperature is set to be $1330^{\circ} \mathrm{C}\left(16.625^{\circ} \mathrm{C} / \mathrm{km}\right)$. Below the base of the lithosphere, temperatures are calculated by linear interpolation between $1330^{\circ} \mathrm{C}$ and $1600^{\circ} \mathrm{C}\left(0.47^{\circ} \mathrm{C} / \mathrm{km}\right)$

\section{Curie temperature and Curie depth}

Assigning a specific temperature to the Curie isotherm is not trivial since Curie point temperature depends on magnetic minerals. Magnetite has been widely employed to map Curie isotherm (corresponding to $580^{\circ} \mathrm{C}$; e.g., Bhattacharyya \& Leu, 1975), although it is a rare mineral as stoichiometric $\mathrm{Fe}_{3} \mathrm{O}_{4}$. Solid solution of magnetite, depending on the percentage of maghemite or hematite, may vary Curie temperature between 300 and $680^{\circ} \mathrm{C}$. Moreover, Haggerty (1978) reported that serpentinization of mafic and ultramafic rocks apt to be present in the lower and upper mantle have Curie temperatures between 
Table 1: Physical and geometrical model parameters. See Table 2 for models details.

\begin{tabular}{lccc}
\hline Variables & Symbols & Value & Dimensions \\
\hline Top temperature & $T t$ & 0 & ${ }^{\circ} \mathrm{C}$ \\
Bottom temperature & $T b$ & 1600 & ${ }^{\circ} \mathrm{C}$ \\
Box height & $H$ & 600 & $\mathrm{~km}$ \\
Box width & $W$ & $4000-6000$ & $\mathrm{~km}$ \\
Pre-exponential constant & $A$ & $1.5 \times 10^{9}$ & $\mathrm{MPa}$ \\
Thermal expansion coefficient & $\alpha$ & $3.5 \times 10^{-5}$ & $1 / \mathrm{K}^{-5}$ \\
Thermal diffusivity & $\kappa$ & $10^{-6}$ & $\mathrm{~m}^{2} / \mathrm{s}$ \\
Thermal conductivity & $k$ & 3.9 & $\mathrm{~W} / \mathrm{mK}$ \\
Heat capacity & $C p$ & 1200 & $\mathrm{Jkg}^{-1} \mathrm{~K}^{-1}$ \\
Reference density & $\rho$ & 3300 & $\mathrm{~kg}^{-m^{3}}$ \\
Gas constant & $\mathrm{R}$ & 8.314 & $\mathrm{Jmol}^{-1} \mathrm{~K}^{-1}$ \\
Gravity acceleration & $\mathrm{g}$ & 9.81 & $\mathrm{~m}^{2} / \mathrm{s}$ \\
\hline
\end{tabular}

${ }_{82} 620^{\circ} \mathrm{C}$ and $1100^{\circ} \mathrm{C}$. Deep magnetic anomaly sources can extend to limits that overpass 83 the conventionally $580^{\circ} \mathrm{C}$ and, that if lower crust is indeed largely mafic and partially 84 serpentinized, the Curie isotherm may be controlled by alloy metal systems with Curie 85 temperatures that exceeding $620^{\circ} \mathrm{C}$ (Haggerty, 1978).

Furthermore, any method for Curie depth estimation has high intrinsic uncertainty related to the choice of fractal parameter and size of the win${ }_{88}$ dow used to discretize maps of the magnetic anomaly (Audet \& Gosselin, ${ }_{89}$ 2019; Mather \& Fullea, 2019), and heat flow data are occasionally perturbed 90 by hydrothermal circulation and suffer from low spatial coverage (Mather 91 et al., 2018). For these reasons, Li et al. (2013) and Li \& Wang (2016) ${ }_{92}$ state that thermal structures can be better constrained through Curie-point 93 depth maps derived from magnetic anomaly data, independent of heat flow 94 measurements. 
Table 2: Selected model parameters.

\begin{tabular}{ccccccccc}
\hline Model & $\kappa$ & $V e l$ & \multicolumn{3}{c}{ Dislocation creep } & \multicolumn{3}{c}{ Diffusion creep } \\
\cline { 4 - 9 } run & $\left(\mathrm{m}^{2} / \mathrm{s}\right)$ & $(\mathrm{cm} / \mathrm{yr})$ & $E(\mathrm{~kJ} / \mathrm{mol})$ & $V\left(\mathrm{~m}^{3} / \mathrm{mol}\right)$ & $n$ & $E(\mathrm{~kJ} / \mathrm{mol})$ & $V\left(\mathrm{~m}^{3} / \mathrm{mol}\right)$ & $n$ \\
\hline 1 & $1.00 \mathrm{E}-06$ & 1 & 350 & 11 & 3.5 & 335 & 4 & 1 \\
2 & $1.00 \mathrm{E}-06$ & 1 & 120 & 11 & 3.5 & 335 & 4 & 1 \\
3 & $1.00 \mathrm{E}-06$ & 1 & 200 & 11 & 3.5 & 335 & 4 & 1 \\
4 & $1.00 \mathrm{E}-06$ & 1 & 250 & 11 & 3.5 & 335 & 4 & 1 \\
5 & $1.00 \mathrm{E}-06$ & 1 & 300 & 11 & 3.5 & 335 & 4 & 1 \\
6 & $1.00 \mathrm{E}-06$ & 4 & 300 & 11 & 3.5 & 335 & 4 & 1 \\
7 & $1.00 \mathrm{E}-06$ & 1.5 & 350 & 11 & 3.5 & 335 & 4 & 1 \\
8 & $1.00 \mathrm{E}-06$ & 2 & 350 & 11 & 3.5 & 335 & 4 & 1 \\
9 & $1.00 \mathrm{E}-06$ & 2 & 400 & 11 & 3.5 & 335 & 4 & 1 \\
\hline
\end{tabular}

\section{Modelling Results}

Our numerical models are designed to study if and how SSC arising at the LAB produces thermal perturbations at Curie point depths. It is well documented (Richter \& Parsons, 1975; Huang et al., 2003) that plate velocity and activation energy of dislocation in the lithospheric mantle have a main role on the development and evolution of SSC and therefore, we have tested the influence of the activation energy and plate velocity. Tested rheological parameters and plate velocity are summarized in Table 2. Our reference model has a plate velocity of $1 \mathrm{~cm} / \mathrm{yr}$, and rheological activation energy for dislocation and diffusion creep of 350 and $335 \mathrm{~kJ} / \mathrm{mol}$, respectively (Karato \& Wu, 1993).

All models start with an initial period where thermal diffusion is the main cooling mechanism until the bottom part of the lithosphere becomes unstable and drips develop. This behaviour has been observed previously in many numerical models (e.g., Morency et al., 2005; Huang et al., 2003; Korenaga \& Jordan, 2003; van Hunen et al., 2005) where the onset of the instabilities happens at lithospheres older than 70 to 90 Myr. The development of SSC does not produce a perturbation on the Curie isotherm immediately. In Model 1, the sublithospheric convective cells affect the upper mantle, but the Curieisotherm remains mainly unperturbed and follows a purely diffusive cooling trend (Figure 3a). The maximum downgoing velocity at $200 \mathrm{~km}$ depth is $\sim 4 \mathrm{~cm} / \mathrm{yr}$, whereas on the 


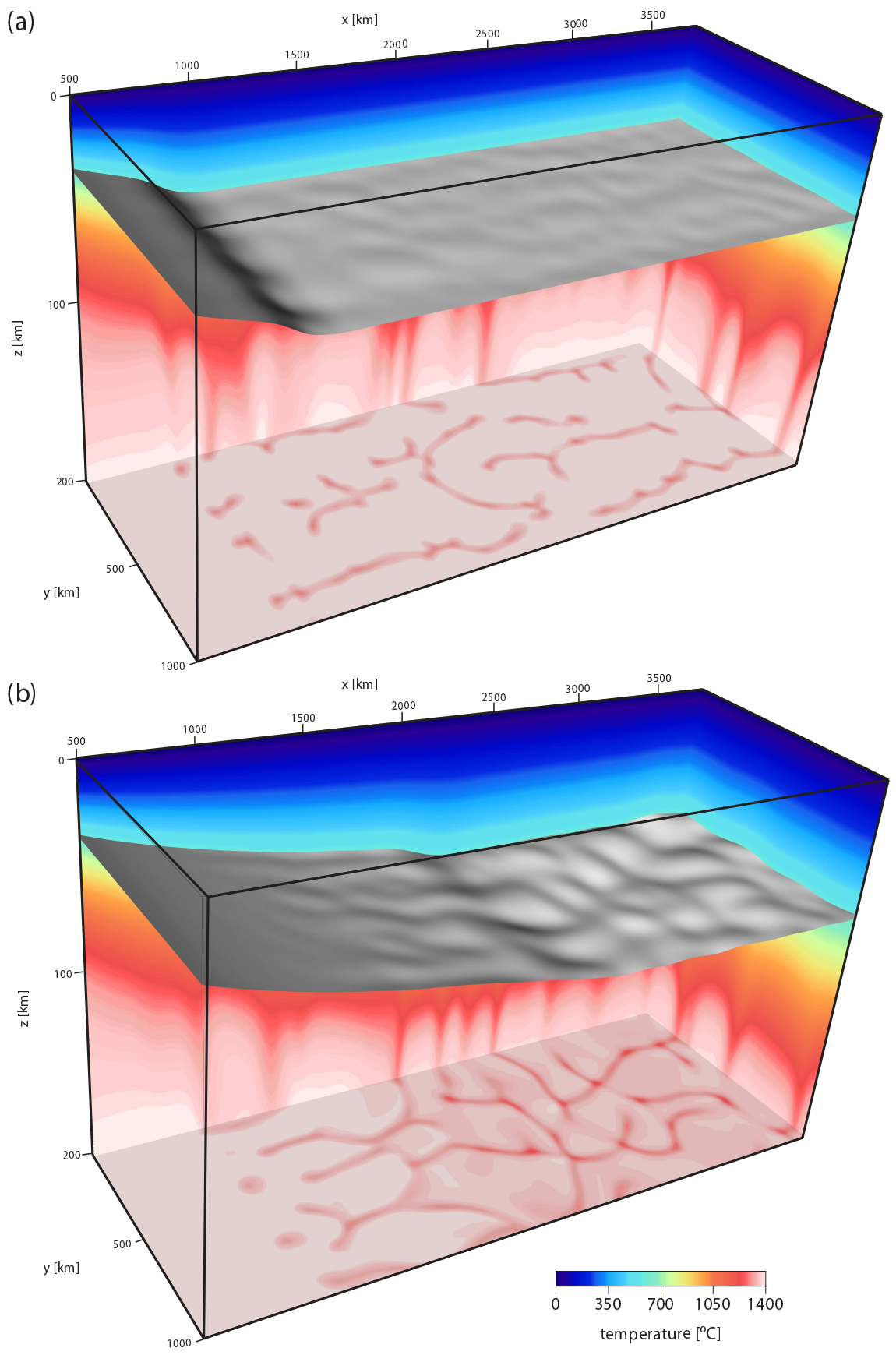

Figure 3: Thermal state of model $1\left(1 \mathrm{~cm} / \mathrm{yr}\right.$ spreading rate, $\left.\mathrm{E}_{\mathrm{disl}}=350 \mathrm{~kJ} / \mathrm{mol}\right)$. 3-D view of the temperature field and Curie isotherm $\left(\mathbf{6 5 0}^{\circ} \mathbf{C}\right.$; gray isotherm) for the top $200 \mathrm{~km}$ of the model domain with a 10-fold vertical exaggeration at scaled simulation time of (a) 90 Myr and (b) $170 \mathrm{Myr}$. 
Curie isotherm, the velocities are negligible. This magnitude coincides with previous works (e.g., Morency et al., 2005).

The Curie isotherm begins to develop vertical variations after $~ 90 \mathrm{Myr}$ when the vigour of the small-scale convection cells becomes stronger. From that time on, the models show perturbations in Curie isotherm closely related to the sublithospheric instabilities (Figure 3b). These perturbations are rather small and have amplitudes from 2 to $4 \mathrm{~km}$ in the complete Curie-temperature range (from 580 to $850^{\circ} \mathrm{C}$ ). Cross sections of the thermal field from the models show a continuous correlation between the perturbation of the Curie-isotherm and the gravitational instability at the LAB (Figures 4 and 5). This correlation indicates that the perturbation of the shallow temperatures arises from the Rayleigh-Taylor instabilities at the LAB.

The perturbations of the Curie isotherm result not only from the thermal propagation of the temperature variations at depth by diffusion, but also from mechanical deformation that arrives at very shallow layers. The convective velocities acting at Curie depths are much smaller in magnitude than the ridge spreading rate. For visualization purposes, the spreading rate has been subtracted from the corresponding velocity component in the velocity field (Figure 4a).

The initial instabilities in a cell pattern have a wavelength ranging between 150 and $300 \mathrm{~km}$. A competition between longitudinal rolls and transverse rolls is observed. Longitudinal rolls, after 170 Myr model time, seem more stable close to the ridge, and are known to develop preferentially in the presence of a shear flow (e.g., imposed velocity; Richter, 1973). Meanwhile, the ridge-parallel instabilities are observed with greater relevance far from the ridge axis. At old ages, the instability pattern develops transverse rolls ending against longitudinal instabilities (Figure 3b). The onset of the small scale convection is stabilized at $\sim 900 \mathrm{~km}$ from the ridge (Figure $3 \mathrm{~b}$ ).

We performed models for different activation energy for dislocation creep (Table 2). All cases display similar dynamics for the development of roll structures. The main difference, as previously shown by Huang et al. (2003) and van Hunen et al. (2005), is that the decrease of the activation energy increases thermomechanical erosion of the base of the lithosphere, but it does not change substantially the generation and development of rolls over the 

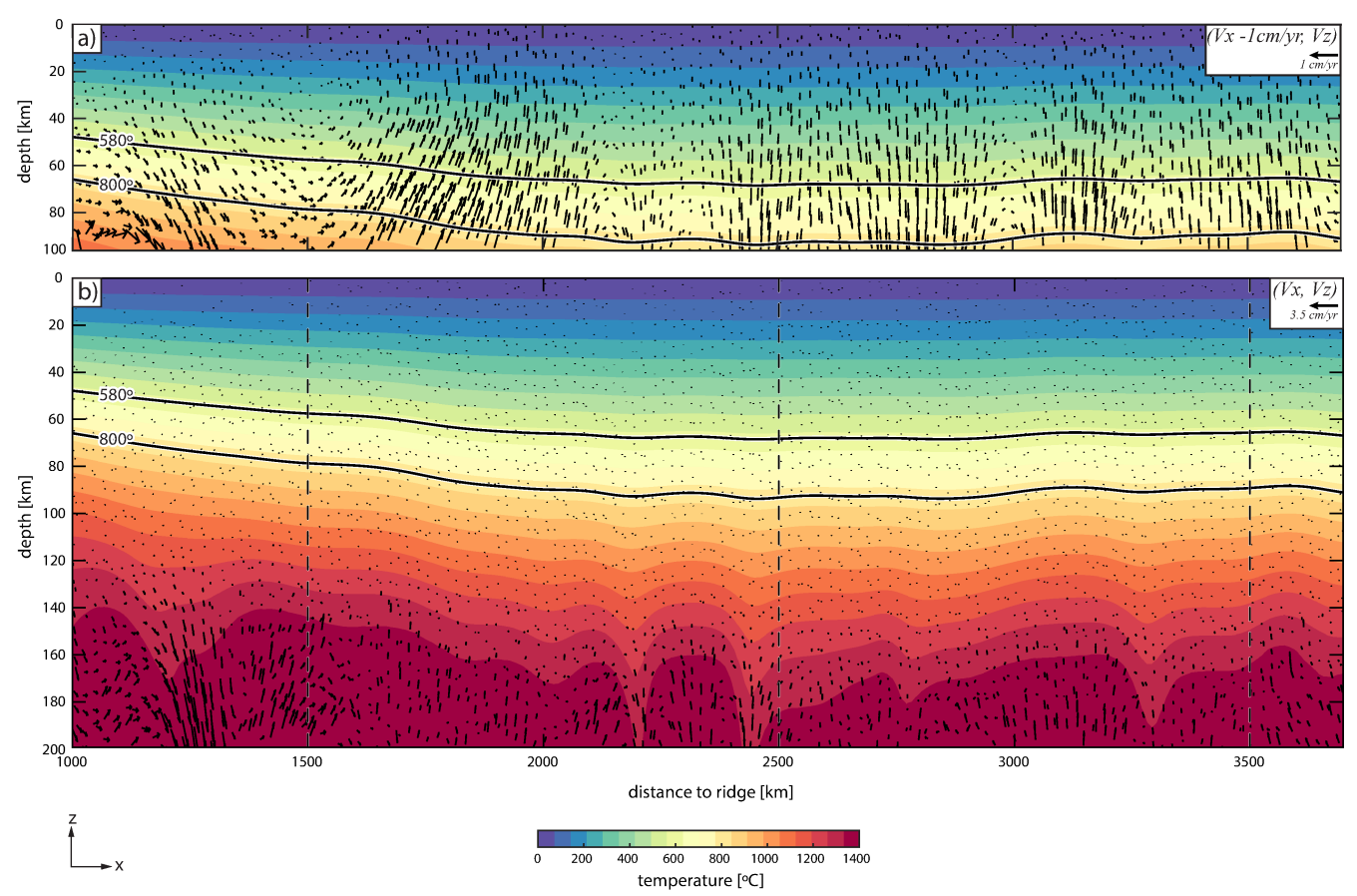

Figure 4: Results obtained for a representative snapshot of the thermal structure for a model $(E=$ $350 \mathrm{~kJ} / \mathrm{mol}$ ) with an imposed velocity of $1 \mathrm{~cm} / \mathrm{yr} .580^{\circ} \mathrm{C}$ and $800^{\circ} \mathrm{C}$ isotherm and velocity fields are displayed on a vertical plane located at $\mathrm{y}=500 \mathrm{~km}$ at a scaled simulation time of $170 \mathrm{Myr}$. (a) Velocity calculated on the first $100 \mathrm{~km}$ depth. Here the velocity in the $\mathrm{x}$ direction is shown as $\mathrm{Vx}-1 \mathrm{~cm} / \mathrm{yr}$ in order to dismiss the influence of the imposed velocity and highlight the vertical one. (b) Velocity calculated on the first $200 \mathrm{~km}$. Dashed line marks the position of the cross section on Figure 5. Maximum velocities are equal to (a) 1.01 and (b) $3.72 \mathrm{~cm} / \mathrm{yr}$. The particles illustrated in these figures represent a small fraction $(1 / 3)$ of the total number of particles used in the numerical calculations. 

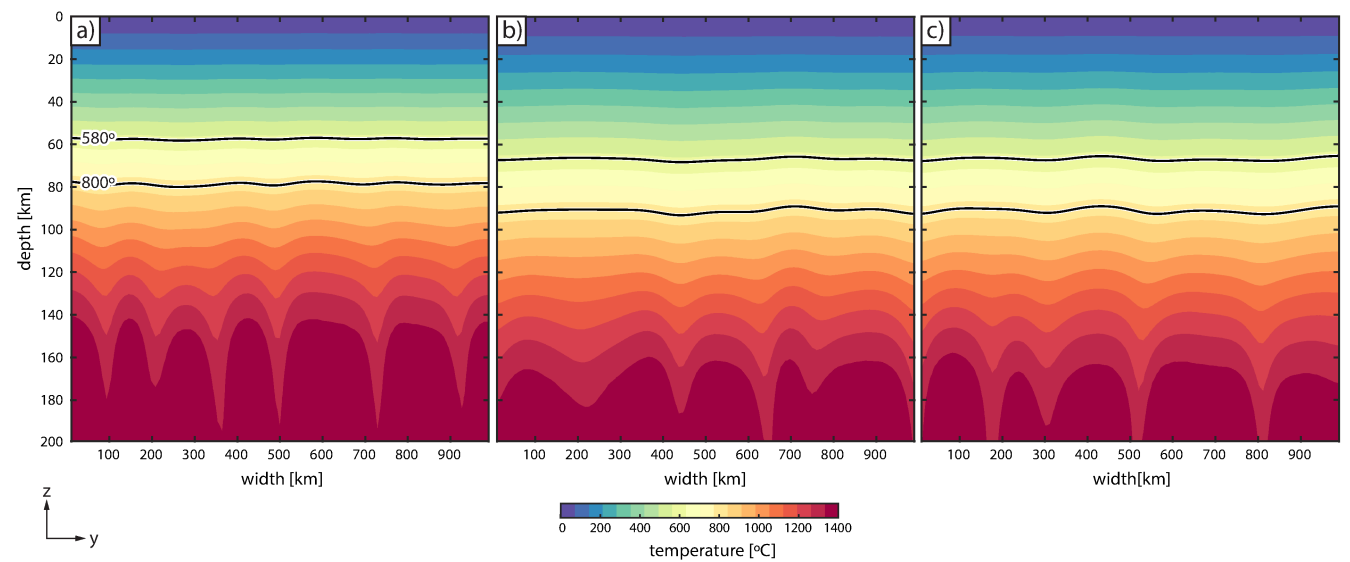

Figure 5: Results obtained for a representative snapshot of the thermal structure for a model $(\mathrm{E}=350$ $\mathrm{kJ} / \mathrm{mol}$ ) with an imposed velocity of $1 \mathrm{~cm} / \mathrm{yr} .580^{\circ} \mathrm{C}$ and $800^{\circ} \mathrm{C}$ isotherm and temperature are displayed on a vertical plane located at (a) $\mathrm{x}=1500 \mathrm{~km}$, (b) $2500 \mathrm{~km}$, and (c) $3500 \mathrm{~km}$ from the ridge, at a scaled simulation time of $170 \mathrm{Myr}$.

Curie isotherm. We quantified the maximum amplitude of the roll structure in all models. Figure 6 shows the resulting maximum amplitude of the Curie isotherm $\left(650^{\circ} \mathrm{C}\right)$, measured on two cross-sections perpendicular to each other, as a function of elapsed model time for models with an imposed velocity of $1 \mathrm{~cm} / \mathrm{yr}$. In general, amplitudes of longitudinal and transverse rolls increase for older lithospheres but it is not possible to observe a direct relationship between maximum amplitudes of rolls and the activation energy values. Which is counterintuitive to the fact that activation energy plays a dominant role in the vigor and amount of small-scale convection (Davaille \& Jaupart, 1994; Korenaga \& Jordan, 2003; van Hunen et al., 2005). However, it is quite similar to what van Hunen \& Zhong (2006) reported in relation to the low dependence of activation energy on the realignment time of rolls. What is worth pointing out is that, as expected for the case $\mathbf{E}=120 \mathrm{~kJ} / \mathrm{mol}$, the amplitudes of the longitudinal and transverse rolls reach their maximum values, $3 \mathrm{~km}$ and $4 \mathrm{~km}$, respectively. Figure 6 a shows that longitudinal rolls maximum amplitude steadily increase from the onset, while the transverse rolls increase their maximum amplitude markedly between the time of the 
a)

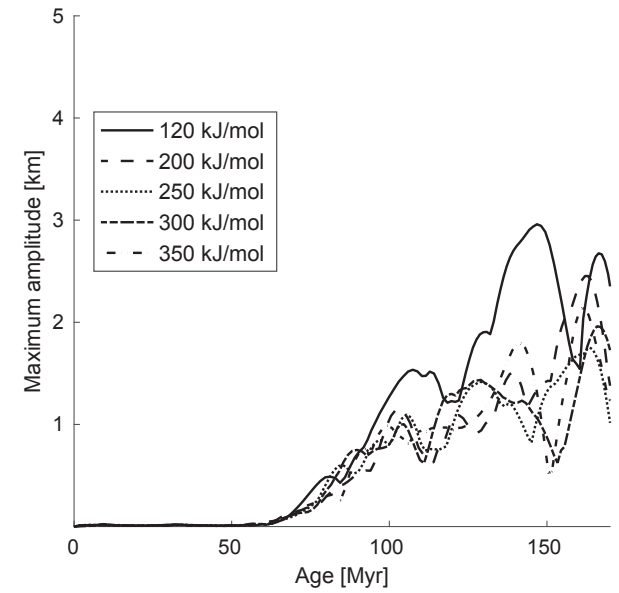

b)

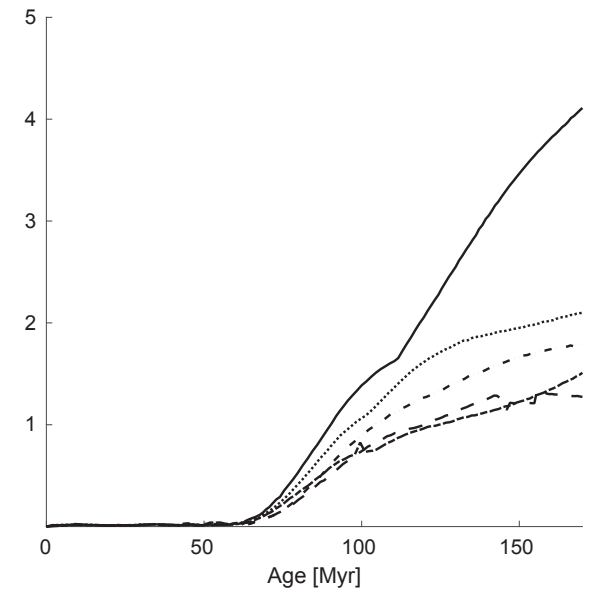

Figure 6: Maximum amplitude of roll structures $\left(650^{\circ} \mathrm{C}\right.$ Curie isotherm) for different activation energy as a function of time for a models with an imposed velocity of $1 \mathrm{~cm} / \mathrm{yr}$. Amplitudes measured in two cross sections at (a) $\mathrm{x}=2000 \mathrm{~km}$ and (b) $\mathrm{y}=500 \mathrm{~km}$.

onset and $120 \mathrm{Myr}$ describing an approximately sigmoid curve (Figure 6b). Models with activation energy of 200,300 and $350 \mathrm{~kJ} / \mathrm{mol}$ achieve maximum amplitude values above $3 \mathrm{~km}$ for longitudinal rolls. While, in the transverse rolls, models with $\mathrm{E}=250$ and $350 \mathrm{~kJ} / \mathrm{mol}$ are close to $2 \mathrm{~km}$, and between 1 and $2 \mathrm{~km}$ for those with $\mathrm{E}=200$ and $300 \mathrm{~kJ} / \mathrm{mol}$.

Our calculations show a cells with a dominant transversal component for the $\mathrm{E}=$ $120 \mathrm{~kJ} / \mathrm{mol}$ (Figure 7a), although it is possible to detect parallel to subparallel transverse rolls and longitudinal rolls developed closer to the ridge and related to the SSC onset. Curie surfaces for models with $E=350 \mathrm{~kJ} / \mathrm{mol}$ (Figure $7 \mathrm{~b}$ ) shows two belts of rolls parallel to the ridge axis at $900 \mathrm{~km}$ from the ridge associated with the SSC onset. It is possible to distinguish transverse rolls at $\sim 2000 \mathrm{~km}$ and a cell with a dominant transversal component arrangement further from the ridge. In this case, the competition between transverse and longitudinal rolls is more visible, and there is no clear preferred orientation. On the contrary, it is more appropriate to point out that the two types of rolls coexist. Even though Curie surface represents a shallow isotherm, the roll structures are present and there is no clear evidence of a preferential orientation. 

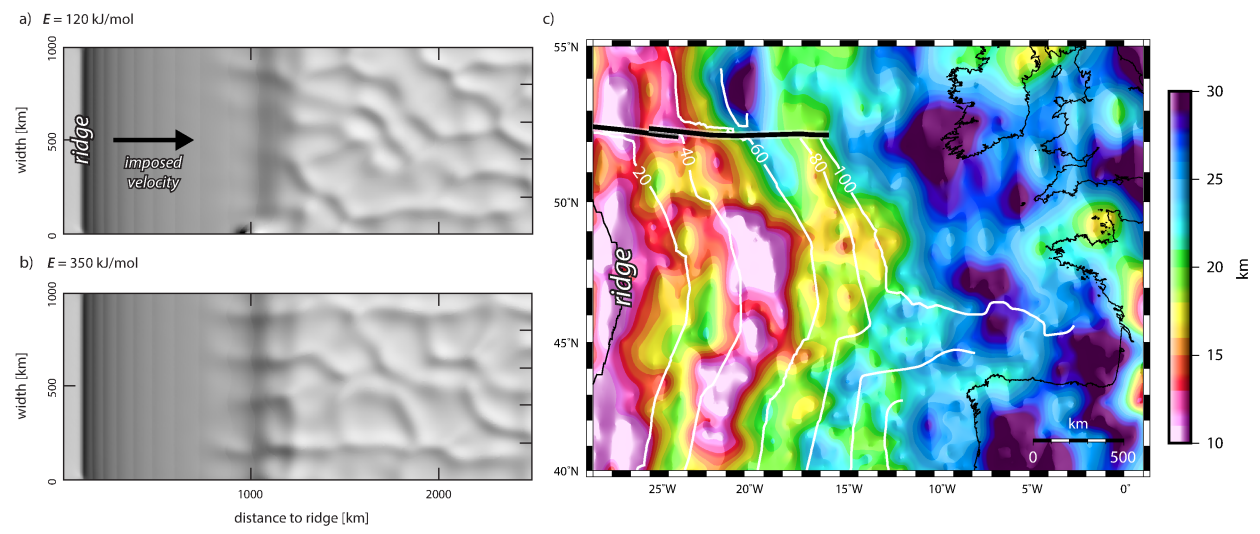

Figure 7: Representative plan view of the Curie isotherm at a scaled simulation time of 90 Myr for (a) $\mathrm{E}=120 \mathrm{~kJ} / \mathrm{mol}$ and (b) $\mathrm{E}=350 \mathrm{~kJ} / \mathrm{mol}$. Both models have $1 \mathrm{~cm} / \mathrm{yr}$ imposed velocity. (c) Curie depth map of the North Atlantic based on inversion of magnetic anomalies from EMAG2 (modified from Li et al., 2013), in Mercator projection and calculated with a window size of 208.8 x $208.8 \mathrm{~km}^{2}$. Thick black line is a fracture zone. Oceanic crust isochrons are based on Müller et al. (2008).

\section{Discussion}

Previous works have studied the small scale convection process and its consequences for the thermal, mechanical and chemical evolution of the oceanic lithosphere (e.g., Richter, 1973; Richter \& Parsons, 1975; van Hunen \& Zhong, 2006; Zlotnik et al., 2008; Afonso et al., 2008). These works concentrate on processes happening at the LAB (1250$1330^{\circ} \mathrm{C}$ ) (e.g., Marquart, 2001; Morency et al., 2005; van Hunen et al., 2005) and pay little attention to the shallower and colder part $\left(580-800^{\circ} \mathrm{C}\right)$ of the lithosphere at Curie depths.

Li et al. (2013) proposed that the observed perturbation of the Curie-temperature isotherms might be a consequence of the deeper SSC processes, implying a link between the deep instabilities at LAB (90 to $100 \mathrm{~km}$ depth) and the shallow perturbations at Curie-depth (40 to $50 \mathrm{~km}$ depth). The modification of the Curie isotherm could be a consequence of mechanical and/or thermal perturbations propagated from the LAB to shallow levels. The anomalies observed in the variations of the Curie depths, if being thermal, have to respond to a recent mechanism like the SSC, as otherwise would have been thermally dissipated.

Our numerical results show that i) the Curie-temperature isotherm can be effectively 
affected by SSC process, and ii) the Curie-depth perturbations resulting from our numerical experiments, for lithospheres older than $80 \mathrm{Myr}$, are somehow compatible with the observations of Li et al. (2013) in terms of wavelengths and amplitudes and, to some degree, with the structure and orientation of the instabilities (e.g. Figure 6). However, it is not possible to do the same correlation for ages younger than 80 Myr because there is no thermal perturbation observed before the onset of SSC. Li et al. (2013) suggested that the onset of SSC is at about $45 \mathrm{Myr}$.

The implications of these results are two folds. The first is that pattern of perturbations of Curie depths observed by Li et al. (2013) in old lithospheres might have been produced by SSC processes. The second implication deals with the SSC process itself; SSC has been proposed and studied by many authors from the observations of bathymetry, surface heat flow and gravity signals at oceanic plates (e.g., Parsons \& McKenzie, 1978; Fleitout \& Yuen, 1984; Stein \& Stein, 1992; Doin \& Fleitout, 1996; Ballmer et al., 2010). However, there is no direct observation of the process; for example, the current resolution of oceanic seismic tomography is not enough to observe individual instabilities. The existence of SSC under the oceanic plates is still under debate (Huang \& Zhong, 2005, and references therein). In this context, the Curie-temperature perturbations might be seen as a new support for the existence of SSC. Curie-temperature data used here is based on magnetic field observations, independent from other observables traditionally used to constrain SSC.

\subsection{Curie depth perturbations after onset of $S S C$}

Richter (1973) and Richter \& Parsons (1975) concluded that transverse rolls are gradually suppressed by the large-scale convective flow. Shear forces at the base of the lithosphere produce a decay in vigor of the transverse rolls that, at some point, are replaced by longitudinal rolls perpendicular to the trench (Marquart, 2001; van Hunen et al., 2005). Previous studies (Rabinowicz et al., 1993; Fujimura \& Kelly, 1993; Sleep, 2011; Wirth \& Korenaga, 2012) show a direct relationship between plate velocity and the decay time of the transverse rolls: fast moving plates suppress transverse rolls faster that slow moving plates. Our results are in agreement with these observations. Initially formed transverse rolls are eventually suppressed and replaced by longitudinal rolls. 
The SSC developing at the base of the lithosphere modifies the lithosphere itself. The deformation generated at the LAB by SSC propagates up until Curie depths (Figures 4 and 5) and imprints there the longitudinal and transverse character of the rolls at depth. The deformation at Curie depth is smaller than at sublithospheric levels, and therefore perturbations have smaller amplitudes and are smoother (longer wavelengths). However, all isotherms in the range of Curie-temperatures $\left(580^{\circ} \mathrm{C}\right.$ to $\left.800^{\circ} \mathrm{C}\right)$ are being modified following the deeper mantle flow (Figures 4 and 5).

Numerical results present a similar structure of instabilities at $\sim 90$ Myr of evolution. Transverse rolls form closer to the ridge axis linked to the SSC onset. At larger distances from the ridge instabilities form a cell with a dominant transversal component pattern mixing rolls types (Figure $7 \mathrm{a}, \mathrm{b}$ ). These observations are similar to those of Rabinowicz et al. (1993) on a two layer viscosity model, where transverse rolls are found to be confined within the top low-viscosity layer and located far from the ridge axis. A similar case, although with different parameter values, is presented by Marquart (2001) for a plate velocity of $1 \mathrm{~cm} / \mathrm{yr}$, in which the $900^{\circ} \mathrm{C}$ isotherm showed a cell with a dominant transversal component pattern for the first 25.7 Myr of evolution time.

Regarding the depth of the Curie isotherms, numerical results show consistently an offset of $\sim 30 \mathrm{~km}$ deeper than those estimated by Li et al. (2013). This difference is produced by the simplified numerical model that does not include explicitly the oceanic crust. The lower thermal conductivity of the oceanic crust rocks will produce a steeper crustal thermal gradient that will move shallow isotherms closer to the surface. In addition, our results are consistent with previous results that suggest that the lithosphere thickness beneath ridges increases as the spreading rate decreases, which is generally consistent with the notion that lateral conductive cooling becomes more important at lower spreading rates (Parmentier \& Morgant, 1990). Curie depth from magnetic inversion can also be underestimated, particularly when using small window sizes ( $\mathrm{Li}$ et al., 2019).

\subsection{Curie depth perturbations before onset of $S S C$}

North Atlantic Curie depths revealed by Li et al. (2013) present shallow belts parallel to the Mid-Atlantic ridge after the $\sim 45$ Myr isochron (Figure $7 \mathrm{c}$ ). At older ages the pattern is more complex, with a larger component of longitudinal rolls and cells with 
a dominant transversal component pattern. Unlike these observations in the North Atlantic, our models do not show oscillations for ages younger than 80 Myr (Figure 7a,b). Therefore, we suggest that shallow oscillations observed at younger ages between $\sim 20$ and 80 Myrs could also result from other processes other than the SSC.

Mantle melting may also affect the dynamics of the system, via melt and/or depletion enhanced buoyancy (Buck \& Su, 1989; Jha et al., 1994; Parmentier \& Morgant, 1990). In addition, melting may also reduce the viscosity of the lithosphere by creating a chemically distinct lithosphere that extends to a relatively constant depth (Gaherty et al., 1996). Many of these processes could be occurring simultaneously, defining the lithosphere at younger ages. As suggested by Harmon et al. (2020), the presence of partial melt is a key variable for small-scale convection to occur at ¡10 Myr seafloor age, and very low mantle viscosities ( $\sim 1017$ Pa.s) are likely required (Buck \& Su, 1989). The presence of partial melt can effectively reduce the mantle viscosity by an order of magnitude or more (Jackson et al., 2006), and could allow small-scale convection to initiate at young ages. The melt could potentially alter the thickness of the lithosphere or eventually pond at its base (Sim et al., 2020; Sparks \& Parmentier, 1991). Upwelling at the ridge could potentially enhance this effect and begin convection at relatively young seafloor ages. As examined by Raddick et al. (2002), melting occurs in upwellings from perturbations in melt fraction (eg. variations in the melting temperature), producing small amounts of melt that can create localized, buoyant upwelling of the mantle. This melting may be enhanced by instabilities that involve positive feedback between decompression melting and the subsequent upwelling caused by the presence of this melt (Tackley \& Stevenson, 1993; Hernlund et al., 2008). These anomalies, combined with what appears to be a lithospheric drip, suggest SSC may be active at relatively young ages, and this could be facilitated by a low - viscosity asthenosphere. In other words, the melt and upwelling could be linked and cause a different pattern of small-scale convection than that predicted by this and previous modeling work that have not taken into account this process. Future models will need to examine the role of melt for enhancing convection and melt migration, its effects on lithospheric evolution and the driving forces of the plates.

Li et al. (2013) and Li \& Wang (2018) noted that the base of magnetic sources may not always correspond to the Curie temperature isotherm but may instead have other 
causes, e.g., contact between serpentinized and non-serpentinized mantle, or be biased by compositional variations. In that context, spreading rate variations might be linked to the Curie-point depth structure. At slower spreading rates, lateral conductive cooling is thought to play an important role in creating thicker lithosphere directly beneath the ridge axis (Parmentier \& Morgant, 1990). At faster spreading rates, the subridge lithosphere may be thinner or nonexistent with dominant volcanic structures. In addition, the spreading rate may dictate the nature of mantle upwelling beneath the ridge faster spreading oceanic plates may produce more 2-D sheet-like upwelling, whereas slow spreading may generate more 3-D diapiric upwelling (Parmentier \& Morgant, 1990). Spreading rate variations have also a strong influence, on the development of the sublithospheric convection (Landuyt \& Ierley, 2012), extent of hydrothermal circulation (Zhou et al., 2020), and the serpentinization process (Iyer et al., 2010). Serpentinization occurs in the presence of fluid pathways (e.g. fractures and faults) and is more important at slow spreading ridges (Iyer et al., 2010). This might be the case of the North Atlantic ridge that shows rate variations during the initial 45 Myr (Müller et al., 2008) coinciding with the oscillations of the Curie Depth temperature at younger ages (Figure 8). At ages older than $45 \mathrm{Myr}$, spreading velocity is nearly constant and therefore variation of the Curie depth cannot be associated.

\section{Conclusions}

We performed models for different activation energy for dislocation creep. The main difference observed was that the decrease of the activation energy increases thermomechanical erosion of the base of the lithosphere, but it did not substantially change the generation and development of rolls over the Curie isotherm. Even though Curie surface represents a shallow isotherm, the roll structures are present and there is no clear evidence of a preferential orientation. These results show that the Curie-temperature isotherm can be effectively affected by SSC process and are compatible with the observations from the North Atlantic lithosphere in terms of wavelengths (150 to $300 \mathrm{~km})$ and amplitudes ( 4 $\mathrm{km}$ ) and, to some degree, with the structure and orientation of the instabilities. Unlike these observations, our models do not show oscillations for ages younger than 80 Myr. Thus, we suggest that shallow oscillations observed at younger ages between $\sim 20$ and 80 


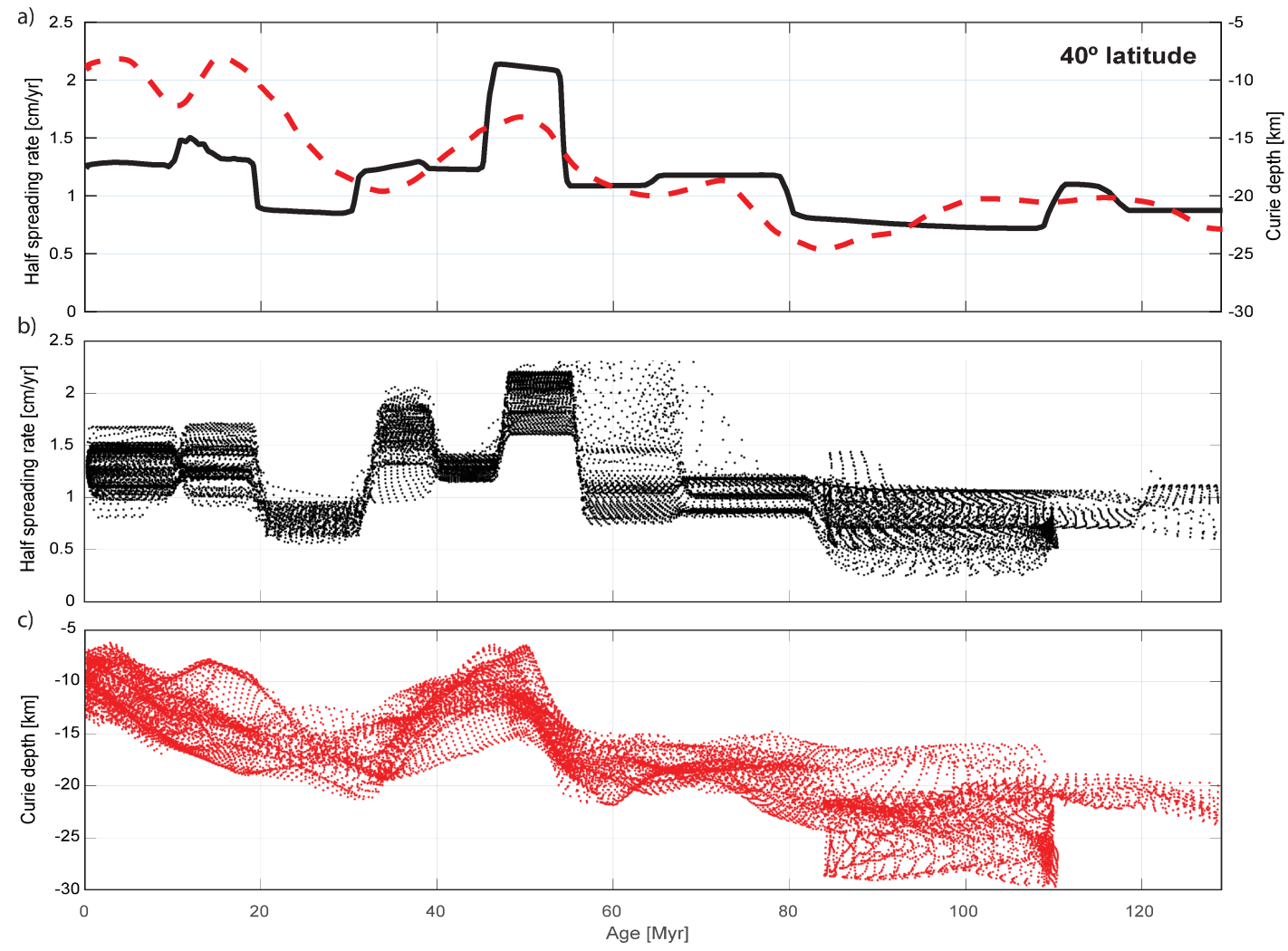

Figure 8: a) Half spreading rate velocity (solid line) and curie depths (red dash line) versus crustal ages through $40^{\circ}$ latitude. Half spreading rate velocity (b) and curie depths (c) versus crustal ages for North Atlantic ocean between $50^{\circ}$ and $40^{\circ}$ latitude. Data from Li et al. (2013) and Müller et al. (2008) 
Myrs could also result from other processes other than the SSC. In the case of the North

Atlantic lithosphere, the spreading rate variation and the melt and upwelling could be intricately linked and could complicate the dynamics and generation of rolls associated directly with the SSC. Future models will need to examine the role of melt for enhancing convection and melt migration, its effects on lithospheric evolution and the driving forces of the plates

Small-scale convection has been proposed as a possible mechanism to explain the observed flattening of several lithospheric signals (bathymetry, surface heat flow, gravity, etc.), however, in this work, we use curie-depth based on magnetic measurements, which are independent of the other observables used to constrain small-scale convection. Thus, the Curie depth perturbation observed in our numerical models could confirm the existence of SSC at isotherms as low as the Curie point.

\section{Acknowledgements}

JL acknowledges the funds project MATHROCKS funded by European Union's Horizon 2020 research and innovation programme under the Marie Sklodowska-Curie grant agreement № 777778 and the Agencia Nacional de Promoción Científica y Tecnológica (PICT 2013-1309 and 2015-1229). SZ acknowledge the funds by Generalitat de Catalunya (grant number 1278 SGR 2017-2019) and Ministerio de Economía y Empresa and Ministerio de Ciencia, Innovación y Universidades (grant number DPI2017-85139-C2-2-R), and the support of the National Natural Science Foundation of China (Grant Nos. 41776057, 41761134051 and 91858213$)$

\section{References}

Afonso, J. C., Zlotnik, S., \& Fernández, M. (2008). Effects of compositional and rheological stratifications on small-scale convection under the oceans: Implications for the thickness of oceanic lithosphere and seafloor flattening. Geophysical Research Letters, 35.

Audet, P., \& Gosselin, J. M. (2019). Curie depth estimation from magnetic anomaly data: a reassessment using multitaper spectral analysis and bayesian inference. Geophysical Journal International, 218, 494-507.

Ballmer, M. D., Ito, G., van Hunen, J., \& Tackley, P. J. (2010). Small-scale sublithospheric convection reconciles geochemistry and geochronology of 'superplume'volcanism in the western and south pacific. Earth and Planetary Science Letters, 290, 224-232. 
Bhattacharyya, B., \& Leu, L.-K. (1975). Spectral analysis of gravity and magnetic anomalies due to two-dimensional structures. Geophysics, 40, 993-1013.

Buck, W. R., \& Su, W. (1989). Focused mantle upwelling below mid-ocean ridges due to feedback between viscosity and melting. Geophysical Research Letters, 16, 641-644.

Davaille, A., \& Jaupart, C. (1994). Onset of thermal convection in fluids with temperature-dependent viscosity: Application to the oceanic mantle. Journal of Geophysical Research: Solid Earth, 99, 19853-19866

Doin, M., \& Fleitout, L. (1996). Thermal evolution of the oceanic lithosphere: an alternative view. Earth and Planetary Science Letters, 142, 121-136.

Eberle, M. A., \& Forsyth, D. W. (1995). Regional viscosity variations, small-scale convection and slope of the depth-age1/2 curve. Geophysical research letters, 22, 473-476.

Fleitout, L., \& Yuen, D. A. (1984). Steady state, secondary convection beneath lithospheric plates with temperature-and pressure-dependent viscosity. Journal of Geophysical Research: Solid Earth, 89, $9227-9244$

Fujimura, K., \& Kelly, R. (1993). Mixed mode convection in an inclined slot. Journal of Fluid Mechanics, $246,545-568$.

Gaherty, J. B., Jordan, T. H., \& Gee, L. S. (1996). Seismic structure of the upper mantle in a central pacific corridor. Journal of Geophysical Research: Solid Earth, 101, 22291-22309.

Haggerty, S. E. (1978). Mineralogical contraints on curie isotherms in deep crustal magnetic anomalies. Geophysical Research Letters, 5, 105-108.

Harmon, N., Rychert, C. A., Kendall, J. M., Agius, M., Bogiatzis, P., \& Tharimena, S. (2020). Evolution of the oceanic lithosphere in the equatorial atlantic from rayleigh wave tomography, evidence for small-scale convection from the pi-lab experiment. Geochemistry, Geophysics, Geosystems, 21, e2020GC009174.

Hernlund, J. W., Tackley, P. J., \& Stevenson, D. J. (2008). Buoyant melting instabilities beneath extending lithosphere: 1. numerical models. Journal of Geophysical Research: Solid Earth, 113.

Huang, J., \& Zhong, S. (2005). Sublithospheric small-scale convection and its implications for the residual topography at old ocean basins and the plate model. Journal of Geophysical Research: Solid Earth, 110 .

Huang, J., Zhong, S., \& van Hunen, J. (2003). Controls on sublithospheric small-scale convection. Journal of Geophysical Research: Solid Earth, 108.

van Hunen, J., Huang, J., \& Zhong, S. (2003). The effect of shearing on the onset and vigor of small-scale convection in a newtonian rheology. Geophysical research letters, 30.

van Hunen, J., \& Zhong, S. (2006). Influence of rheology on realignment of mantle convective structure with plate motion after a plate reorganization. Geochemistry, Geophysics, Geosystems, 7.

van Hunen, J., Zhong, S., Shapiro, N. M., \& Ritzwoller, M. H. (2005). New evidence for dislocation creep from 3-d geodynamic modeling of the pacific upper mantle structure. Earth and Planetary Science Letters, 238, 146-155.

Iyer, K., Rüpke, L. H., \& Morgan, J. P. (2010). Feedbacks between mantle hydration and hydrothermal 
convection at ocean spreading centers. Earth and Planetary Science Letters, 296, 34-44.

Jackson, I., Faul, U. H., Gerald, J. D. F., \& Morris, S. (2006). Contrasting viscoelastic behavior of melt-free and melt-bearing olivine: Implications for the nature of grain-boundary sliding. Materials Science and Engineering: A, 442, 170-174.

Jha, K., Parmentier, E., \& Morgan, J. P. (1994). The role of mantle-depletion and melt-retention buoyancy in spreading-center segmentation. Earth and Planetary Science Letters, 125, 221-234.

Karato, S.-i., \& Wu, P. (1993). Rheology of the upper mantle: A synthesis. Science, 260, 771-778.

Kirby, S. H. (1983). Rheology of the lithosphere. Reviews of Geophysics, 21, 1458-1487.

Korenaga, J., \& Jordan, T. H. (2003). Physics of multiscale convection in earth's mantle: Onset of sublithospheric convection. Journal of Geophysical Research: Solid Earth, 108.

Landuyt, W., \& Ierley, G. (2012). Linear stability analysis of the onset of sublithospheric convection. Geophysical Journal International, 189, 19-28.

Li, C.-F., Lu, Y., \& Wang, J. (2017). A global reference model of curie-point depths based on emag2. Scientific reports, 7, 45129.

Li, C.-F., \& Wang, J. (2016). Variations in moho and curie depths and heat flow in eastern and southeastern asia. Marine Geophysical Research, 37, 1-20.

Li, C.-F., \& Wang, J. (2018). Thermal structures of the pacific lithosphere from magnetic anomaly inversion. Earth and Planetary Physics, 2, 52-66.

Li, C.-F., Wang, J., Lin, J., \& Wang, T. (2013). Thermal evolution of the north atlantic lithosphere: new constraints from magnetic anomaly inversion with a fractal magnetization model. Geochemistry, Geophysics, Geosystems, 14, 5078-5105.

Li, C.-F., Zhou, D., \& Wang, J. (2019). On application of fractal magnetization in curie depth estimation from magnetic anomalies. Acta Geophysica, 67, 1319-1327.

Marquart, G. (2001). On the geometry of mantle flow beneath drifting lithospheric plates. Geophysical Journal International, 144, 356-372.

Mather, B., \& Fullea, J. (2019). Constraining the geotherm beneath the british isles from bayesian inversion of curie depth: integrated modelling of magnetic, geothermal, and seismic data. Solid Earth, 10, 839-850.

Mather, B., McLaren, S., Taylor, D., Roy, S., \& Moresi, L. (2018). Variations and controls on crustal thermal regimes in southeastern australia. Tectonophysics, 723, 261-276.

Maus, S., Barckhausen, U., Berkenbosch, H., Bournas, N., Brozena, J., Childers, V., Dostaler, F., Fairhead, J., Finn, C., Von Frese, R. et al. (2009). Emag2: A 2-arc min resolution earth magnetic anomaly grid compiled from satellite, airborne, and marine magnetic measurements. Geochemistry, Geophysics, Geosystems, 10 .

Morency, C., Doin, M.-P., \& Dumoulin, C. (2005). Three-dimensional numerical simulations of mantle flow beneath mid-ocean ridges. Journal of Geophysical Research: Solid Earth, 110.

Moresi, L., Quenette, S., Lemiale, V., Meriaux, C., Appelbe, B., \& Mühlhaus, H.-B. (2007). Computational approaches to studying non-linear dynamics of the crust and mantle. Physics of the Earth and Planetary Interiors, 163, 69-82. 
Müller, R. D., Sdrolias, M., Gaina, C., \& Roest, W. R. (2008). Age, spreading rates, and spreading asymmetry of the world's ocean crust. Geochemistry, Geophysics, Geosystems, 9.

Nagata, T. (1961). Rock magnetism. Maruzen Company.

Parmentier, E., \& Morgant, J. P. (1990). Spreading rate dependence of three-dimensional structure in oceanic spreading centres. Nature, 348, 325-328.

Parsons, B., \& McKenzie, D. (1978). Mantle convection and the thermal structure of the plates. J. geophys. Res, 83, 4485-4496.

Rabinowicz, M., Rouzo, S., Sempere, J.-C., \& Rosemberg, C. (1993). Three-dimensional mantle flow beneath mid-ocean ridges. Journal of Geophysical Research: Solid Earth, 98, 7851-7869.

Raddick, M. J., Parmentier, E., \& Scheirer, D. S. (2002). Buoyant decompression melting: A possible mechanism for intraplate volcanism. Journal of Geophysical Research: Solid Earth, 107, ECV-7.

Ranalli, G. (1995). Rheology of the Earth. Springer Science \& Business Media.

Richter, F. M. (1973). Convection and the large-scale circulation of the mantle. Journal of Geophysical Research, 78, 8735-8745.

Richter, F. M., \& Parsons, B. (1975). On the interaction of two scales of convection in the mantle. Journal of Geophysical Research, 80, 2529-2541.

Sim, S. J., Spiegelman, M., Stegman, D. R., \& Wilson, C. (2020). The influence of spreading rate and permeability on melt focusing beneath mid-ocean ridges. Physics of the Earth and Planetary Interiors, (p. 106486).

Sleep, N. H. (2011). Small-scale convection beneath oceans and continents. Chinese Science Bulletin, $56,1292-1317$.

Sparks, D. W., \& Parmentier, E. (1991). Melt extraction from the mantle beneath spreading centers. Earth and Planetary Science Letters, 105, 368-377.

Stein, C. A., \& Stein, S. (1992). s. Nature, 359, 123-129.

Tackley, P., \& Stevenson, D. (1993). A mechanism for spontaneous self-perpetuating volcanism on the terrestrial planets. In Flow and Creep in the Solar System: Observations, Modeling and Theory (pp. 307-321). Springer.

Wirth, E. A., \& Korenaga, J. (2012). Small-scale convection in the subduction zone mantle wedge. Earth and Planetary Science Letters, 357, 111-118.

Zhou, D., Li, C.-F., Zlotnik, S., \& Wang, J. (2020). Correlations between oceanic crustal thickness, melt volume, and spreading rate from global gravity observation. Marine Geophysical Research, 41, 1-16.

Zlotnik, S., Afonso, J. C., Díez, P., \& Fernández, M. (2008). Small-scale gravitational instabilities under the oceans: Implications for the evolution of oceanic lithosphere and its expression in geophysical observables. Philosophical magazine, 88, 3197-3217. 